\title{
STRATEGI PENGEMBANGAN USAHA PRODUK TEH CELUP ROSELA (Hibiscus sabdariffa L.) UD. BALI GENDIS, KLUNGKUNG
}

\author{
Tamara Isabela ${ }^{1}$, Sri Mulyani. ${ }^{2}$, I Ketut Satriawan ${ }^{2}$ \\ ${ }^{1}$ Mahasiswa Jurusan Teknologi Industri Pertanian, FakultasTeknologi Pertanian Unud \\ ${ }^{2}$ Dosen Jurusan Teknologi Industri Pertanian, Fakultas Teknologi Pertanian Unud
}

Email: tamaraisabela41@gmail.com ${ }^{1}$

Email koresponden: srimulyani@ unud.ac.id²

\begin{abstract}
This study aims to identify the internal and external factors, analyzing alternative strategy, and recommends priority strategy. This research using matrix IFE, EFE, SWOT, IE and TOPSIS (Technique for Order of Preference by Similarity to Ideal Solution). The results show that the company has 5 strengths, 6 weaknesses, 4 opportunities and 4 threats in this business. The results showed that the value of internal factor evaluation (IFE) was 3,350 and external factor evaluation (EFE) was 3,063. This value indicated a strong position. In the matrix Internal-External (IE) strategy that must be done was to grow and develop a strategy, which consists an intensive strategies (market penetration, market development and product development) and integrative strategies (backward integration, forward integration, and horizontal integration. Based on SWOT analysis there are 7 alternative strategies that can be recommended to develop UD. Bali Gendis. The result of strategy ranking analysis is promoting periodically and socializing the benefits of rosela tea actively to introduce more products to the public.
\end{abstract}

Keywords:industrial development strategy, UD. Bali gendis, rosela tea, SWOT, TOPSIS.

\section{PENDAHULUAN}

Pertumbuhan ekonomi sangat diperlukan oleh setiap negara sebab dengan adanya peningkatan pertumbuhan ekonomi dapat menunjukkan kesejahteraan yang tercermin pada peningkatan output perkapita serta diikuti dengan daya beli masyarakat yang meningkat (Yunan, 2009). Pertumbuhan ekonomi ditandai dengan bertumbuhnya sektor ekonomi masyarakat contohnya di bidang industri. Salah satu sektor industri yang mengalami pertumbuhan cukup pesat adalah sektor makanan dan minuman. Banyaknya industri yang berkembang membuat perusahaan harus dapat mengikuti dan menghadapi perubahan yang terjadi baik itu dalam bidang ekonomi, teknologi, politik dan budaya. Setiap perusahaan memiliki strategi pengembangan yang berbeda dalam menghadapi perubahan. Jika perusahaan memiliki strategi yang tidak tepat maka akan mengakibatkan kesulitan bagi perusahaan tersebut dalam menghadapi tingginya tuntutan pelanggan.

Salah satu usaha yang bergerak di bidang industri minuman adalah UD. Bali Gendis. UD. Bali Gendis merupakan home industry yang memproduksi teh celup rosela. Nugroho (2009) menjelaskan bahwa bunga rosela mempunyai kandungan antosianin, betakaroten, vitamin $\mathrm{C}$, tiamin, riboflavin, flavonoid dan niasin. Selain itu Hayati dkk (2012) juga mengatakan bahwa kandungan kimia yang berperan sebagai antioksidan dalam kelopak bunga rosela adalah pigmen antisianin yang termasuk dalam golongan flavonoid. Kelopak bunga rosela juga mengandung vitamin $\mathrm{C}$ dalam kadar tinggi yang berfungsi untuk meningkatkan daya tahan tubuh manusia terhadap serangan penyakit. Kandungan vitamin $\mathrm{C}$ rosela lebih tinggi dibandingkan dengan jeruk dan mangga (Mardiah, 2009).

UD. Bali Gendis mengakui bahwa dalam menghadapi persaingan di dunia industri yang pesat terlebih dalam memproduksi teh celup rosela, membutuhkan strategi yang tepat untuk dapat mempertahankan usahanya. Perusahaan harus mengidentifikasi lingkungan internal dan eksternal perusahaan 
yang bertujuan untuk mengetahui kekuatan dan kelemahan yang dimiliki serta dapat memanfaatkan peluang dan mengendalikan ancaman yang ada. Penelitian penyusunan strategi pengembangan usaha produk teh celup rosela UD. Bali Gendis bertujuan untuk menganalisis kondisi internal dan eksternal yang berkaitan dengan usaha yang akan dikembangkan, dan menyusun serta merekomendasikan strategi pengembangan usaha.

\section{METODE PENELITIAN}

Penelitian ini dilaksanakan di UD. Bali Gendis yang berlokasi di Jl. Sauh Kabeh Br. Tengah Dawan Kelod, Klungkung, Bali. Pengumpulan data dilaksanakan pada bulan Oktober - November 2017. Data yang digunakan dalam penelitian ini adalah data primer yang berupa gambaran umum perusahaan, analisis lingkungan internal perusahaan yakni produksi, pemasaran, keuangan, sumber daya manusia, dan analisis lingkungan eksternal perusahaan yakni kompetitor, pemasok dan pemerintah. Selain itu, penelitian juga menggunakan data sekunder yang berupa sumber informasi mengenai hasil penelitian yang terkait dengan topik, studi literatur dari buku dan artikel. Pakar terdiri dari produsen teh celup rosela UD. Bali Gendis, Distributor teh celup rosela UD. Bali Gendis, dan Dosen Fakultas Teknologi Pertanian. Metode pengolahan dan analisis data yang digunakan dalam penelitian ini menggunakan analisis SWOT (Strength, Weakness, Oppurtunities, Threath), Matriks Internal Factor Evaluation (IFE), Matriks External Factor Evaluation (EFE), Matriks Internal-Eksternal (IE) dan metode Tehnique for Order Preference by Similarity to Ideal Solution (TOPSIS).

\section{HASIL DAN PEMBAHASAN}

\section{Gambaran Umum UD. Bali Gendis}

UD. Bali Gendis merupakan suatu usaha industri dengan skala rumah tangga yang berdiri sejak tahun 2009. Usaha ini didirikan oleh Bapak Nengah Mulyadi dan Ibu Ketut Rustini yang berlokasi di daerah Klungkung, tepatnya di Jalan Sauh Kabeh Br. Tengah Dawan Kelod, Klungkung, Bali. Perusahaan memproduksi beberapa produk seperti gula herbal, teh rosela, teh daun insulin dan teh daun jati cina. Perusahaan juga sudah memiliki sertifikat HALAL dari MUI dengan No. 08120003200810 dan izin PIRT dengan No.309510502051. Kapasitas produksi perusahaan sebesar $36 \mathrm{~kg}$ basah kelopak bunga rosela setiap kali produksi. Proses produksi masih menggunakan alat yang sederhana yaitu blender dan alat press. Bahan baku diperoleh dari lahan sendiri dan sebagian dipasok dari kota Solo. UD. Bali Gendis tidak memiliki struktur organisasi yang baku, karena usaha ini adalah milik keluarga, dan dikelola oleh anggota keluarga.

\section{Analisis Lingkungan Perusahaan}

Analisis lingkungan perusahaan dibagi menjadi 2 yaitu analisis lingkungan internal dan analisis lingkungan eksternal. Analisis lingkungan internal meliputi produksi, pemasaran, keuangan dan sumber daya manusia, sedangkan analisis lingkungan eksternal meliputi kompetitor, pemasok dan pemerintah.

\section{Analisis Lingkungan Internal}

Hunger dan Wheleen (2003) mengidentifikasi faktor-faktor strategis internal, yaitu kekuatan dan kelemahan yang juga akan menentukan apakah perusahaan mampu mengambil keuntungan dari peluangpeluang yang ada sambil menghindari ancaman-ancaman. Faktor lingkungan internal UD. Bali Gendis yaitu:

\section{1) Produksi}


Proses produksi teh celup rosela diawali dengan penyiapan bahan baku dari kelopak rosela yang sudah dipisah dari bijinya kemudian dicuci dan dikeringkan dengan cahaya matahari selama 3-4 hari. Kelopak rosela kering kemudian dihaluskan menggunakan blender. Setelah dihaluskan, bubuk rosela kemudian dikemas menggunakan kantung teh dan di-press menggunakan mesin press. Takaran bubuk teh untuk setiap kantung teh adalah 1 gram per kantung teh. Kemasan sekunder menggunakan kotak teh yang terbuat dari bahan kardus. Teh celup rosela yang sudah dikemas disimpan di tempat yang kering dan tidak lembab.

\section{2) Pemasaran}

Pemasaran terkait dengan bauran pemasaran, yaitu: aspek produk, harga, distribusi dan promosi. Produk yang dihasilkan UD. Bali Gendis adalah teh celup rosela. Pada kemasan produk sudah dilengkapi dengan label HALAL dari MUI dan PIRT dari Dinas Kesehatan, komposisi produk, merk, dan tanggal kadaluarsa. Kemasan suatu produk yang baik harus terdiri dari nama dan alamat produsen, label HALAL, nomor PIRT, kode produksi, berat bersih, tanggal kadaluarsa, komposisi produk. Harga teh celup rosela adalah Rp. 15.000 per kotak, tiap satu kotak teh memiliki berat 25 gram dengan isi 25 kantung teh. Perusahaan menentukan harga jual berdasarkan biaya-biaya yang dikeluarkan untuk setiap satuan produk ditambah dengan keuntungan yang dikehendaki. Perusahaan mendistribusikan produknya dengan 2 cara, yaitu: melalui reseller dan secara langsung kepada konsumen. Dalam mempromosikan produknya, perusahaan mengikuti beberapa kegiatan seperti Small and Medium Enterprises and Cooperatives (SMESCO) dan pameran di Renon yang diadakan oleh Dinas Pertanian setiap bulan September.

\section{3) Keuangan}

Keuangan dikelola langsung oleh pemilik UD. Bali Gendis. Pemasukan dan pengeluaran diolah secara manual. Sumber modal usaha ini berasal dari modal pribadi dan pinjaman dari BRI. Modal ini dikelola oleh perusahaan untuk proses produksi hingga produk terjual.

\section{4) Sumber Daya Manusia}

UD. Bali Gendis dikelola langsung oleh pemiliknya dan dibantu 4 orang karyawan. Karyawan yang bekerja di UD. Bali Gendis direkrut secara kekeluargaan. Pemilik usaha selalu mengikuti pelatihan kerja yang diberikan oleh Dinas Pertanian, Dinas Perindustrian dan Dinas Perdagangan. Pelatihan kerja tersebut kemudian diterapkan dan diajarkan kembali kepada karyawan agar setiap karyawan mengetahui dasar-dasar perusahaan dan pekerjaan yang dikerjakan.

\section{Analsis Lingkungan Eksternal}

David (2011) menjelaskan tujuan dari analisis lingkungan eksternal adalah untuk mengembangkan daftar terbatas peluang yang dapat dimanfaatkan perusahaan dan ancaman yang harus dihindari. Faktor lingkungan eksternal UD. Bali Gendis meliputi:

\section{1) Kompetitor}

Ada banyak persaingan di dunia industri, termasuk di industri pangan. Kompetitor biasanya membawa hal-hal baru dalam dunia industri, baik itu teknologi yang lebih modern ataupun tenaga kerja yang terdidik dan ahli. Kompetitor juga mampu menghasilkan dan memasarkan produk serupa ataupun 
menawarkan produk substitusi dengan manfaat yang relatif sama. Perusahaan sejenis yang menjadi kompetitor UD. Bali Gendis adalah UD. Taman Medis, CV. Banyumili dan My Own Farm.

\section{2) Pemasok}

UD. Bali Gendis hanya memiliki satu pemasok bunga rosela yang berasal dari Solo. Pemasok pada waktu tertentu masih menaikkan harga bahan baku. Selain itu juga terdapat keterlambatan pemasok dalam hal pengiriman bahan baku yang sering terjadi. Hal ini dapat menghambat proses produksi karena kurangnya ketersediaan bahan baku.

\section{3) Pemerintah}

Perusahaan bekerja sama dengan pemerintah Kota Denpasar seperti Dinas Perindustrian dan Perdagangan yang juga memberikan pelatihan kerja berupa pembukuan sederhana keuangan, kemasan produk, produksi yang aman serta penyuluhan dan sosialisasi mengenai beberapa perizinan yang harus dimiliki oleh sebuah usaha, khususnya dalam bidang pangan. Ommani (2011) dalam penelitiannya menjelaskan bahwa dukungan pemerintah menjadi salah satu strategi yang berperan penuh dalam pengembangan manajemen sistem pertanian di iran.

\section{Identifikasi Faktor Internal dan Eksternal}

Berdasarkan hasil analisis lingkungan internal dan eksternal perusahaan diperoleh beberapa faktor lingkungan internal dan faktor lingkungan eksternal usaha teh celup rosela Bali Gendis. Faktor-faktor internal dan eksternal dapat dilihat pada Tabel 1. dan 2.

Tabel 1. Faktor Strategis Internal

\begin{tabular}{|c|c|c|}
\hline Kekuatan & \multicolumn{2}{|r|}{ Kelemahan } \\
\hline $\begin{array}{l}\text { 1. Harga mampu bersaing dengan } \\
\text { produk sejenis } \\
\text { 2. Memiliki cita rasa dan aroma khas } \\
\text { teh wangi rosela } \\
\text { 3. Memiliki sertifikat HALAL dari } \\
\text { MUI } \\
\text { 4. Ada expired date pada produk } \\
\text { 5. Sudah ada izin PIRT dari Dinas } \\
\text { Kesehatan }\end{array}$ & $\begin{array}{ll}\text { 1. Gamba } \\
\text { produk } \\
\text { 2. Desain } \\
\text { 3. Belum } \\
\text { mempe } \\
\text { udara 1 } \\
\text { 4. Tidak } \\
\text { Senyau } \\
\text { 5. Promo } \\
\text { 6. Proses } \\
\text { alam }\end{array}$ & $\begin{array}{l}\text { pada kemasan tidak sesuai dengan } \\
\text { emasan kurang menarik } \\
\text { da kemasan sekunder untuk } \\
\text { ahankan agar produk kedap terhadap } \\
\text { ar dan aroma tidak hilang } \\
\text { anya informasi detail produk (kandungan } \\
\text { ) pada kemasan } \\
\text { belum optimal } \\
\text { engeringan produk masih mengandalkan }\end{array}$ \\
\hline \multicolumn{3}{|l|}{ abel 2. Faktor Strategis Eksternal } \\
\hline Peluang & & Ancaman \\
\hline $\begin{array}{l}\text { 1. Produk yang dihasilkan tidak bertentang } \\
\text { budaya masyarakat. } \\
\text { 2. Meningkatnya kesadaran masyarakat ter } \\
\text { sebagai minuman yang berkhasiat bagi t } \\
\text { mengandung antioksidan } \\
\text { 3. Perubahan pola pikir masyarakat yang m } \\
\text { pola hidup sehat } \\
\text { 4. Potensi pengembangan pasar masih besa } \\
\text { produksi teh celup rosela di kawasan Ba } \\
\text { masih terbatas }\end{array}$ & $\begin{array}{l}\text { In dengan } \\
\text { buh karena } \\
\text { engadopsi } \\
\text { karena } \\
\text { Timur }\end{array}$ & $\begin{array}{l}\text { 1. Produk sejenis dengan kemasan yang } \\
\text { lebih menarik dan menjadi market } \\
\text { leader } \\
\text { 2. Cuaca yang tidak menentu yang } \\
\text { berpengaruh terhadap proses } \\
\text { pengeringan bunga rosela } \\
\text { 3. Ketersediaan dan harga bahan baku } \\
\text { yang tidak stabil } \\
\text { 4. Produk teh lain yang memiliki } \\
\text { manfaat fungsional sejenis seperti } \\
\text { jasmine dan chamomile }\end{array}$ \\
\hline
\end{tabular}

\section{Tahap Input (Input Stage)}

Pada tahap input pengolahan data dilakukan menggunakan matriks IFE dan matriks EFE. Hasil analisis matriks IFE lebih rinci dapat dilihat pada Tabel 3. dan hasil analisis matriks EFE dapat dilihat pada Tabel 4. 


\section{Matriks Internal Factor Evaluation (IFE)}

Berdasarkan hasil analisis yang dilihat pada Tabel 3 dapat dilihat UD. Bali Gendis memiliki 2 kekuatan utama yaitu produk sudah memiliki izin MUI dan PIRT, serta produk juga sudah memiliki expired date dengan skor total 0,401. Selain memiliki kelebihan, perusahaan juga memiliki kelemahan yaitu gambar pada kemasan tidak sesuai dengan produk, dengan nilai skor 0,296. Skor total matriks IFE adalah 3,350 hal ini menunjukkan bahwa UD. Bali Gendis mampu memanfaatkan kekuatan yang dimiliki untuk mengatasi kelemahan yang ada.

\section{Matriks External Factor Evaluation (EFE)}

Berdasarkan hasil analisis yang dilihat pada Tabel 4. dapat dilihat UD. Bali Gendis memiliki peluang utama yaitu produk yang dihasilkan tidak bertentangan dengan budaya masyarakat dengan nilai skor 0,542. Selain itu, UD. Bali Gendis juga memiliki ancaman utama yaitu ketersediaan dan harga bahan baku yang tidak stabil dengan nilai 0,384. Skor total matriks EFE adalah 3,063, hal ini menunjukkan bahwa UD. Bali Gendis mampu memanfaatkan peluang yang dimiliki untuk mengatasi ancaman yang ada.

Tabel 3. Matriks Internal Factor Evaluation (IFE)

\begin{tabular}{lllll}
\hline No. & \multicolumn{1}{c}{ Kekuatan (A) } & $\begin{array}{l}\text { Bobot } \\
(\mathbf{a})\end{array}$ & $\begin{array}{l}\text { Rating } \\
(\mathbf{b})\end{array}$ & $\begin{array}{l}\text { Nilai } \\
\mathbf{a ~ x ~ b = c}\end{array}$ \\
\hline 1 & Harga mampu bersaing dengan produk sejenis & 0,083 & 3,4 & 0,281 \\
2 & Memiliki cita rasa dan aroma khas teh wangi rosela & 0,096 & 3,6 & 0,347 \\
3 & Memiliki sertifikat HALAL dari MUI & 0,092 & 3,8 & 0,349 \\
4 & Ada expired date pada produk & 0,106 & 3,8 & 0,401 \\
5 & Produk memiliki izin PIRT dari DINAS KESEHATAN & 0,106 & 3,8 & 0,401 \\
& Kelemahan (B) & & \\
1 & Gambar pada kemasan tidak sesuai dengan produk & 0,087 & 3,4 & 0,296 \\
2 & Desain kemasan kurang menarik & 0,083 & 3,2 & 0,264 \\
3 & Belum ada kemasan sekunder untuk mempertahankan agar & 0,087 & 3,0 & 0,261 \\
& produk kedap terhadap udara luar dan aroma tidak hilang & & \\
4 & Tidak adanya informasi detail produk (kandungan & 0,087 & 3,0 & 0,261 \\
5 & senyawa) pada kemasan & 0,087 & 3,0 & 0,261 \\
6 & Promosi belum optimal & 0,087 & 2,6 & 0,227 \\
\hline & Proses pengeringan produk masih mengandalkan alam & $\mathbf{1 , 0 0 0}$ & & $\mathbf{3 , 3 5 0}$ \\
\hline
\end{tabular}

Tabel 4. Matriks External Factor Evaluation (EFE)

\begin{tabular}{llccc}
\hline No. & \multicolumn{1}{c}{ Peluang (A) } & Bobot & Rating & $\begin{array}{c}\text { Nilai } \\
(\mathbf{c = a x b})\end{array}$ \\
\hline 1 & $\begin{array}{l}\text { Produk yang dihasilkan tidak bertentangan dengan budaya } \\
\text { masyarakat }\end{array}$ & 0,151 & 3,6 & 0,542 \\
2 & $\begin{array}{l}\text { Meningkatnya kesadaran masyarakat terhadap teh sebagai } \\
\text { minuman yang berkhasiat bagi kesehatan tubuh karena }\end{array}$ & 0,130 & 3,4 & 0,442 \\
3 & $\begin{array}{l}\text { mengandung antioksidan } \\
\text { Perubahan pola pikir masyarakat yang mengadopsi pola hidup } \\
\text { sehat }\end{array}$ & 0,123 & 3,4 & 0,419 \\
4 & $\begin{array}{l}\text { Potensi pengembangan pasar masih besar karena produksi teh } \\
\text { celup rosela di kawasan Bali Timur masih terbatas }\end{array}$ & 0,110 & 3,4 & 0,373 \\
1 & $\begin{array}{l}\text { Produk sejenis dengan kemasan yang lebih menarik dan } \\
\text { menjadi market leader }\end{array}$ & 0,130 & 2,6 & 0,338 \\
2 & $\begin{array}{l}\text { Cuaca yang tidak menentu yang berpengaruh terhadap proses } \\
\text { pengeringan bunga rosela } \\
\text { Ketersediaan dan harga bahan baku yang tidak stabil }\end{array}$ & 0,123 & 2,4 & 0,296 \\
4 & $\begin{array}{l}\text { Produk teh lain yang memiliki manfaat fungsional sejenis } \\
\text { seperti jasmine dan chamomile }\end{array}$ & 0,137 & 2,8 & 0,384 \\
\hline & Total EFE (A + B) & $\mathbf{1 , 0 0 0}$ & 2,8 & 0,268 \\
\hline & & $\mathbf{3 , 0 6 3}$ \\
\hline
\end{tabular}




\section{Tahap Pencocokan (Matching Stage)}

Pada tahap pencocokan pengolahan data dilakukan dengan menggunakan matriks IE. Analisis ini merupakan tahap 2 yaitu pencocokan yang digunakan untuk mempermudah dalam memberikan pemilihan alternatif strategi. Berdasarkan hasil analisis pada tahap 1 diperoleh nilai skor EFE adalah 3,063 dan nilai skor IFE adalah 3,350. Dari nilai tersebut jika dipetakan pada tabel IE maka posisi perusahaan berada pada sel 1 yang menggambarkan bahwa perusahaan berada dalam kondisi internal kuat dan eksternal tinggi. Matriks IE dapat dilihat pada Gambar 2. Strategi yang digunakan untuk perusahaan berada pada sel I (strategi tumbuh dan kembangkan), yaitu terdiri dari strategi intensif (penetrasi pasar, pengembangan pasar dan pengembangan produk) atau strategi integratif (integrasi ke belakang, integrasi ke depan dan integrasi horizontal).

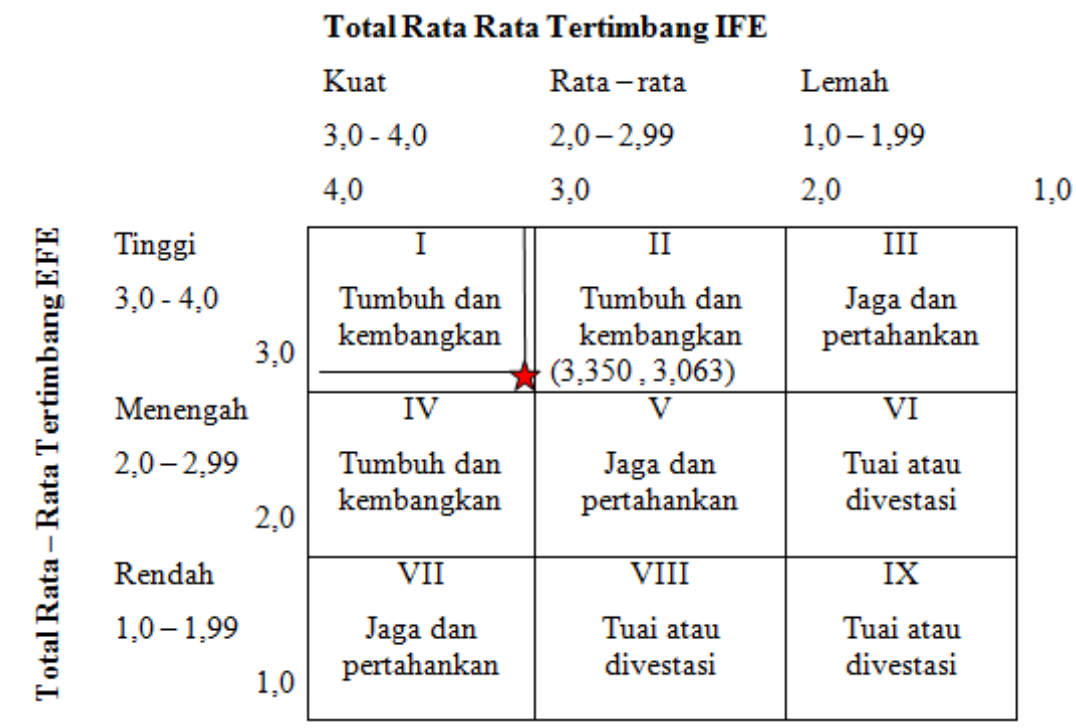

Keterangan: symbol (ㅊ) bintang menunjukkan titik strategi yang digunakan

Gambar 2. Hasil Analisis Matriks IE (Internal External)

\section{Analisis Matriks SWOT}

Analisis SWOT sering digunakan sebagai metode untuk mengidentifikasi faktor - faktor kunci yang mempengaruhi keberhasilan atau kegagalan suatu proyek ataupun usaha industri (Geneletti dkk, 2007). Matriks SWOT menggambarkan bagaimana manajemen dapat mencocokkan peluang-peluang dan ancamanancaman eksternal yang dihadapi suatu perusahaan dengan kekuatan dan kelemahan internalnya. Hasil analisis matriks SWOT dapat dilihat pada tabel 5. Berdasarkan matriks SWOT terdapat 7 kemungkinan alternatif strategi yang dapat digunakan oleh UD. Bali Gendis, yaitu:

\section{1) Strategi $S$ - O(Strengths - Opportunities)}

Strategi S-O adalah strategi yang menggunakan kekuatan internal UD. Bali Gendis untuk memanfaatkan peluang yang ada. Strategi yang dapat diterapkan adalah sebagai berikut :

a) Memperluas pasar dengan cara menjual produk ke outlet-outlet dan warung kecil. Novi (2016) menyatakan bahwa untuk memperluas pasar dapat dilakukan dengan cara memberikan nomor telepon pemesanan pada label barang dan memproduksi lebih banyak.

b) Meningkatkan brand image bahwa teh celup rosela Bali Gendis merupakan produk minuman herbal berbahan dasar bunga rosela. Heriyati dan Septi (2012) menyatakan bahwa variabel brand image dan 
kualitas produk berpengaruh secara signifikan terhadap keputusan pembelian sedangkan sisanya 46,9\% dipengaruhi oleh variabel lain.

\section{2) Strategi S - T (Strengths - Treats)}

Strategi S-T adalah strategi yang menggunakan kekuatan internal UD. Bali Gendis untuk menghindari atau mengurangi pengaruh dari ancaman yang ada. Strategi yang dapat diterapkan adalah mempertahankan harga dan kualitas produk. Yu dan Kincade (2001) menunjukkan bahwa citra produk berpengaruh secara positif dan signifikan terhadap perceived quality dan performance expectation pada tahap evaluasi, selanjutnya keinginan untuk membeli pada tahap pembelian dipengaruhi oleh harga, dan kepuasan setelah pembelian dipengaruhi oleh citra produk disertai kinerja produk.

\section{3) Strategi W - O (Weaknesses - Opportunities)}

Strategi W-O adalah strategi untuk mengatasi kelemahan internal UD. Bali Gendis dengan memanfaatkan peluang yang dimiliki. Arila dkk (2013) menjelaskan bahwa promosi yang dilakukan oleh UD. Bali Gendis dalam mempromosikan produk teh bunga rosela adalah dengan menggunakan metode personal selling (penjualan perorangan) dan informasi dari mulut ke mulut (word of mouth) dan belum pernah mencoba mempromosikan produknya melalui media elektronik maupun media cetak. Kendala pemasaran yang dihadapi perusahaan yang selanjutnya adalah kendala dalam sisi sosialnya. Saat ini masyarakat belum terlalu mengenal manfaat dari teh rosela dan masih banyak yang belum mengetahui apa itu teh bunga rosela. Hal ini akan semakin menyulitkan UD. Bali Gendis dalam menjual produknya. Salah satu cara yang telah ditempuh oleh perusahaan adalah dengan rajin menghadiri lokakarya atau seminarseminar sehingga bisa memperkenalkan produknya ke masyarakat umum. Strategi W - O yang dapat diterapkan perusahaan adalah melakukan promosi secara berkala dan sosialisasi manfaat teh rosela secara aktif untuk lebih memperkenalkan produk ke masyarakat luas.

\section{4) Strategi W - T (Weakness - Threath)}

Strategi W-Tadalah strategi untuk meminimalkan kelemahan internal UD. Bali Gendis dan menghindari ancaman yang ada. Strategi $\mathrm{W}$ - T yang dapat diterapkan perusahaan adalah sebagai berikut:

a) Melakukan kerjasama yang bersifat mengikat dengan pihak pemasok. Purwono dkk (2015) menyatakan bahwa dengan memastikan bahan baku tersedia akan memungkinkan dalam menjalani strategi ini. Kendali atas pemasok bahan baku dapat dilakukan pada beberapa pemasok agar ketersediaan bahan baku selalu ada. Juliani dkk (2017) juga menyatakan bahwa dengan memastikan bahan baku tersedia tepat waktu dan tepat jumlah dapat menghindari terhambatnya proses produksi.

b) Membuat kemasan produk yang lebih menarik dari produk sejenis lainnya. Nuryanti dan Rahman (2008) dalam penelitiannya menjelaskan bahwa kemasan Teh Kotak Ultrajaya yang terdiri dari bentuk, bahan, warna, gambar, dan label berpengaruh positif dan signifikan terhadap keputusan pembelian. Secara keseluruhan total pengaruh kemasan terhadap keputusan pembelian adalah sebesar 53,40\%.

c) Menggunakan alat oven dalam proses pengeringan bunga rosela. Suherman (2012) menjelaskan bahwa bunga rosela yang baru dipanen memiliki kadar air sekitar $85 \%$. Pada proses pengeringan rosela dapat menggunakan alat Recirculated Tray Dryers (pengering multi rak). Pengeringan rosela dengan alat ini 
hanya membutuhkan waktu 100 menit untuk mengeringkan rosela sampai kadar air $14 \%$ tiap 250 gr bunga rosela.

Tabel 5. Hasil analisis matriks SWOT

\begin{tabular}{|c|c|c|}
\hline & $\begin{array}{l}\text { Faktor Peluang / Opportunities } \\
\text { (O) : } \\
\text { 1. Produk yang dihasilkan } \\
\text { tidak bertentangan dengan } \\
\text { budaya masyarakat } \\
\text { 2. Meningkatnya kesadaran } \\
\text { masyarakat terhadap teh } \\
\text { sebagai minuman yang } \\
\text { berkhasiat bagi kesehatan } \\
\text { tubuh karena mengandung } \\
\text { antioksidan } \\
\text { 3. Perubahan pola pikir } \\
\text { masyarakat yang } \\
\text { mengadopsi pola hidup } \\
\text { sehat } \\
\text { 4. Potensi pengembangan } \\
\text { pasar masih besar karena } \\
\text { produksi teh celup rosela di } \\
\text { kawasan Bali Timur masih } \\
\text { terbatas. }\end{array}$ & $\begin{array}{l}\text { Faktor Ancaman / Treats }(\mathrm{T}) \text { : } \\
\text { 1. Produk sejenis dengan } \\
\text { kemasan yang lebih } \\
\text { menarik dan menjadi } \\
\text { market leader } \\
\text { 2. Cuaca yang tidak menentu } \\
\text { yang berpengaruh terhadap } \\
\text { proses pengeringan bunga } \\
\text { rosela } \\
\text { 3. Ketersediaan dan harga } \\
\text { bahan baku yang tidak stabil } \\
\text { 4. Produk teh lain yang } \\
\text { memiliki manfaat } \\
\text { fungsional sejenis seperti } \\
\text { jasmine dan chamomile. }\end{array}$ \\
\hline $\begin{array}{l}\text { Faktor Kekuatan/Strenght (S) } \\
: \\
\text { 1. Harga mampu bersaing } \\
\text { dengan produk sejenis } \\
\text { 2. Memiliki cita rasa dan } \\
\text { aroma khas teh wangi } \\
\text { Rosela } \\
\text { 3. Memiliki sertifikat } \\
\text { HALAL dari MUI } \\
\text { 4. Ada expired date pada } \\
\text { produk } \\
\text { 5. Produk sudah memiliki } \\
\text { izin PIRT dari DINAS } \\
\text { KESEHATAN }\end{array}$ & \begin{tabular}{l}
\multicolumn{1}{c}{$\mathrm{S}-\mathrm{O}$} \\
1. \\
Memperluas pasar dengan \\
cara menjual produk ke \\
outlet-outlet dan warung \\
kecil $\left(\mathrm{S}_{1}, \mathrm{~S}_{2}, \mathrm{~S}_{3}, \mathrm{~S}_{4}, \mathrm{~S}_{5}, \mathrm{O}_{1}\right.$, \\
$\left.\mathrm{O}_{4}\right)$ \\
2. Meningkatkan brand image \\
bahwa teh celup rosela UD. \\
Bali Gendis merupakan \\
produk minuman herbal \\
berbahan dasar bunga \\
Rosela $\left(\mathrm{S}_{2}, \mathrm{~S}_{4}, \mathrm{~S}_{5}, \mathrm{O}_{2}, \mathrm{O}_{3}\right)$
\end{tabular} & $\begin{array}{l}\mathrm{S}-\mathrm{T} \\
\text { 1. Mempertahankan harga dan } \\
\text { kualitas produk }\left(\mathrm{S}_{1}, \mathrm{~S}_{2}, \mathrm{~S}_{3} \text {, }\right. \\
\left.\mathrm{S}_{4}, \mathrm{~S}_{5}, \mathrm{~T}_{1}, \mathrm{~T}_{4}\right)\end{array}$ \\
\hline \begin{tabular}{|ll}
\multicolumn{2}{l}{ Faktor Kelemahan / } \\
Weaknesses $(\mathrm{W}):$ \\
1. & Gambar pada kemasan \\
& tidak sesuai dengan produk \\
2. & Desain kemasan kurang \\
menarik \\
3.
\end{tabular} & \begin{tabular}{l}
\multicolumn{1}{c}{$\mathrm{W}-\mathrm{O}$} \\
1. Melakukan promosi secara \\
berkala dan sosialisasi \\
manfaat teh rosela secara \\
aktif untuk lebih \\
memperkenalkan produk ke \\
masyarakat luas $\left(\mathrm{W}_{5}, \mathrm{O}_{1}\right.$, \\
$\left.\mathrm{O}_{2}, \mathrm{O}_{3}, \mathrm{O}_{4}\right)$
\end{tabular} & \begin{tabular}{l}
\multicolumn{1}{c}{$\mathrm{W}-\mathrm{T}$} \\
1. Melakukan kerjasama yang \\
bersifat mengikat dengan \\
pihak pemasok $\left(\mathrm{W}_{5}, \mathrm{~T}_{3}\right)$ \\
2. Membuat kemasan produk \\
yang lebih menarik dari \\
produk sejenis lainnya $\left(\mathrm{W}_{1}\right.$, \\
$\left.\mathrm{W}_{2}, \mathrm{~W}_{3}, \mathrm{~W}_{4}, \mathrm{~T}_{1}\right)$ \\
3. Menggunakan alat oven \\
artifisial dalam proses \\
pengeringan bunga rosela \\
$\left(\mathrm{W}_{6}, \mathrm{~T}_{2}\right)$
\end{tabular} \\
\hline
\end{tabular}


Alternatif strategi yang dihasilkan dimasukkan ke dalam strategi yang telah dirumuskan pada matriks IE yaitu tumbuh dan kembangkan, yaitu:

1. Strategi Penetrasi Pasar

Strategi ini merupakan strategi dimana perusahaan mencari cara untuk meningkatkan pangsa pasar untuk produk yang ada dalam pasar saat ini dengan usaha pemasaran yang besar. Dengan mempertahankan harga dan kualitas produk, melakukan promosi secara berkala dan sosialisasi manfaat teh rosela secara aktif untuk lebih memperkenalkan produk ke masyarakat luas, serta meningkatkan brand image bahwa teh celup rosela UD. Bali Gendis merupakan produk herbal berbahan dasar bunga rosela.

2. Strategi Pengembangan Pasar

Strategi ini merupakan strategi dimana perusahaan mengenalkan produk yang ada ke area yang baru. Dengan menjual produk ke outlet-outlet baru dan warung kecil dapat memperluas pasar.

3. Strategi Pengembangan Poduk

Strategi ini merupakan strategi dimana perusahaan mencari peningkatan penjualan dengan meningkatkan atau memodifikasi produk yang ada. Dengan strategi membuat kemasan produk yang lebih menarik dari produk sejenis lainnya dan menggunakan alat oven dalam proses pengeringan bunga rosela.

4. Strategi Integrasi ke Belakang

Strategi ini merupakan strategi yang mencari kepemilikan atau meningkatkan kontrol atas pemasok perusahaan dimana perusahaan melakukan kerjasama yang bersifat mengikat dengan pihak pemasok.

5. Strategi Integrasi ke Depan

Strategi ini merupakan strategi yang memperoleh kepemilikan atau meningkatkan kontrol atas distributor. Saat ini perusahaan belum dapat melaksanakan strategi ini, karena produk yang ditawarkan perusahaan adalah produk baru dengan jenis yang sudah ada sebelumnya dipasarkan oleh perusahaan lain.

6. Strategi Integrasi Horizontal

Strategi ini merupakan strategi yang mencari kepemilikan atau meningkatkan kontrol atas kompetitor perusahaan. Saat ini perusahaan belum dapat melakukan strategi ini, karena perusahaan tergolong masih baru dibandingkan dengan perusahaan lainnya. Hal ini membuat perusahaan sulit untuk meningkatkan kontrol atas pesaing.

\section{Tahap Keputusan (Decision Stage)}

Tahap terakhir adalah tahap keputusan dengan metode Technique for Order of Preferenceby Similarity to Ideal Solution (TOPSIS). Metode ini banyak digunakan untuk menyelesaikan pengambilan keputusan secara praktis. Hal ini disebabkan konsepnya sederhana dan mudah dipahami dan efisien serta memiliki kemampuan mengukur kinerja relatif dari alternatif-alternatif keputusan (Kusumadewi dkk, 2006). Konsep dasar dari metode ini adalah alternatif yang dipilih harus memiliki jarak terpendek ke solusi ideal positif dan jarak terjauh dari solusi ideal negatif (Evangelos, 2000). Dalam perhitungan TOPSIS dibutuhkan kriteria dan 
alternatif yang menjadi dasar dalam menentukan prioritas strategi pengembangan usaha. Alternatif penilaian dapat dilihat pada Tabel 6 dan kriteria dapat dilihat pada Tabel 7.

Tabel 6. Alternatif

\begin{tabular}{cl}
\hline Alternatif & \multicolumn{1}{c}{ Keterangan } \\
\hline K1 & Memperluas pasar dengan cara menjual produk ke outlet-outlet dan \\
K2 & Warung \\
Meningkatkan brand image bahwa teh celup rosela UD. Bali Gendis \\
K3 & merupakan produk minuman herbal berbahan dasar bunga rosela \\
K4 & $\begin{array}{l}\text { Melakukanankan harga dan kualitas produk } \\
\text { secara aktif untuk lebih memperka benalkan produk ke masyarakat luas }\end{array}$ \\
K5 & Melakukan kerjasama yang bersifat mengikat dengan pihak pemasok \\
K6 & Membuat kemasan produk yang lebih menarik dari produk sejenis \\
K7 & $\begin{array}{l}\text { lainnya } \\
\text { Menggunakan alat oven artifisial dalam proses pengeringan bunga } \\
\text { rosela }\end{array}$ \\
\hline
\end{tabular}

Tabel 7. Kriteria

\begin{tabular}{cc}
\hline Alternatif $\left(\mathbf{A}_{\mathbf{i}}\right)$ & Keterangan \\
\hline A1 & Kekuatan \\
A2 & Kelemahan \\
A3 & Peluang \\
A4 & Ancaman \\
\hline
\end{tabular}

Metode TOPSIS menghasilkan nilai preferensi yang dapat dilihat pada Tabel 8. Strategi yang memiliki nilai preferensi paling tinggi terdapat pada alternatif K4 dengan nilai 1,000. Dengan nilai preferensi 1,000 dapat disimpulkan bahwa strategi melakukan promosi secara berkala dan sosialisasi manfaat teh rosela secara aktif untuk lebih memperkenalkan produk ke masyarakat luas menjadi prioritas strategi. Alternatif strategi kedua yang terpilih adalah K2 dengan nilai 0,684, alternatif strategi ketiga yang terpilih adalah K5 dengan nilai 0,680, alternatif strategi keempat yang terpilih adalah $\mathrm{K} 1$ dengan nilai 0,440, alternatif strategi kelima yang terpilih adalah K7 dengan nilai 0,410, alternatif strategi keenam yang terpilih adalah K3 dengan nilai 0,247 dan alternatif strategi ketujuh yang terpilih adalah K6 dengan nilai 0,000.

Tabel 8. Nilai preferensi

\begin{tabular}{|c|c|c|c|}
\hline No. & $\begin{array}{l}\text { Alternatif } \\
\text { Strategi }\end{array}$ & Keterangan & $\begin{array}{c}\text { Nilai } \\
\text { Preferensi }\end{array}$ \\
\hline 1. & $\mathrm{~K} 1$ & $\begin{array}{l}\text { Memperluas pasar dengan cara menjual produk ke outlet-outlet dan } \\
\text { warung }\end{array}$ & 0,440 \\
\hline 2. & K2 & $\begin{array}{l}\text { Meningkatkan brand image bahwa teh celup rosela UD. Bali Gendis } \\
\text { merupakan produk minuman herbal berbahan dasar bunga rosela }\end{array}$ & 0,684 \\
\hline 3. & K3 & Mempertahankan harga dan kualitas produk & 0,247 \\
\hline 4. & K4 & $\begin{array}{l}\text { Melakukan promosi secara berkala dan sosialisasi manfaat teh rosela } \\
\text { secara aktif untuk lebih memperkenalkan produk ke masyarakat luas }\end{array}$ & 1,000 \\
\hline 5. & K5 & Melakukan kerjasama yang bersifat mengikat dengan pihak pemasok & 0,680 \\
\hline 6. & K6 & $\begin{array}{l}\text { Membuat kemasan produk yang lebih menarik dari produk sejenis } \\
\text { lainnya }\end{array}$ & 0000 \\
\hline 7. & K7 & $\begin{array}{l}\text { Menggunakan alat oven artifisial dalam proses pengeringan bunga } \\
\text { rosela }\end{array}$ & 0,410 \\
\hline
\end{tabular}

\section{KESIMPULAN DAN SARAN}

\section{Kesimpulan}

1) Hasil penelitian menunjukkan bahwa terdapat 5 faktor kekuatan dan 6 faktor kelemahan. Kekuatan utamanya adalah (1) produk memiliki expired date, (2) produk teh celup rosella sudah memiliki izin 
PIRT, sedangkan kelemahan utamanya adalah gambar pada kemasan tidak sesuai dengan produk. UD. Bali Gendis juga memiliki 4 peluang dan 4 ancaman. Peluang utamanya adalah produk yang dihasilkan tidak bertentangan dengan budaya masyarakat, sedangkan ancaman terbesar yang dihadapi UD. Bali Gendis adalah ketersediaan dan harga bahan baku yang tidak stabil.

2) Strategi yang digunakan oleh UD. Bali Gendis adalah strategi tumbuh dan kembangkan yang terdiri dari strategi intensif (penetrasi pasar, pengembangan pasar, dan pengembangan produk) atau strategi integratif (integrasi ke belakang, integrasi ke depan, dan integrasi horizontal). Berdasarkan alternatifalternatif dari matriks SWOT diperoleh 7 strategi untuk mengembangkan usaha teh celup rosela UD. Bali Gendis. Prioritas strategi adalah melakukan promosi secara berkala dan sosialisasi manfaat teh rosela secara aktif untuk lebih memperkenalkan produk ke masyarakat luas.

\section{Saran}

1) UD. Bali Gendis dapat memanfaatkan kekuatan dan peluang yang dimiliki untuk mengembangkan usaha dengan cara memperluas pasar dengan menjual produk ke outlet-outlet dan warung serta meningkatkan brand image bahwa teh celup rosela UD. Bali Gendis merupakan produk minuman herbal berbahan dasar bunga rosela. UD. Bali Gendis juga harus mempertahankan harga dan kualitas produk, memiliki kerjasama yang mengikat dengan pihak pemasok, membuat kemasan yang lebih menarik dan menggunakan alat oven dalam proses pengeringan bunga rosela.

2) UD. Bali Gendis dapat menerapkan prioritas strategi terpilih yaitu melakukan promosi secara berkala dan sosialisasi manfaat teh rosela secara aktif untuk lebih memperkenalkan produk ke masyarakat luas.

\section{DAFTAR PUSTAKA}

Arila, J., I. N. G. Ustriyana dan I. A. L. Dewi. 2013. Titik Impas dan Bauran Pemasaran Bunga Rosela pada UD. Bali Gendis di Desa Dawan Kelod Kecamatan Dawan Kabupaten Klungkung. Jurnal Agribisnis dan Agrowisata. 2 (3) : 109 - 118.

David, F. 2011. Manajemen Strategi Konsep. Salemba Empat. Jakarta.

Geneletti D., Bagli S., Napolitano P. and Pistocchi A. (2007), Spatial decision support for strategic environmental assessment of land use plans. A case study in southern Italy, Environmental Impact Assessment Review. Journal of Civil and Environmental Engineering. 27 (5) : 408-423. http://www.sciencedirect.com/science/article/pii/ S0195925507000170

Hayati E. K., Budi U. S. dan Hermawan R. 2012. Konsentrasi total senyawa antosianin ekstrak kelopak bunga rosela (Hibiscus sabdariffa L.) : pengaruh temperatur dan pH. Jurnal Kimia. 6 (2) : 138 - 147.

Heriyati, P. dan Septi . 2012. Analisis Pengaruh Brand Image dan Kualitas Produk Terhadap Keputusan Pembelian Konsumen pada Handphone Nexian. Journal of Business Strategy and Execution. 4 (2) : 171-205

Hunger, J. dan Wheelen, L. T. 2003. Manajemen Strategis. Andi. Yogyakarta.

Juliani, K. A. M., Harsojuwono, B. A. Dan I Ketut Satriawan. 2017. Strategi Pengembangan Usaha Minuman Barjaz Tea di Barjaz Company. Jurnal Rekayasa dan Manajemen Agroindustri. 5 (4) : 41 50 . 
Kusumadewi, S., Hartati, S., Harjoko, A. dan Wardoyo, R. 2006. Fuzzy Multi-Attribute Decision Making. Graha Ilmu. Yogyakarta.

Mardiah. 2009. Budi Daya dan Pengolahan Rosela Si Merah Segudang Manfaat. Jakarta Selatan : Agromedia.

Nugroho W.B. 2009. Aktivitas Antioksidan Fraksi n-Heksan, Eter, dan Air Ekstrak Metanolik Daun Rosela (Hibiscus sabdariffa L.) Terhadap Radikal DPPH. Skripsi Fakultas Farmasi Universitas Setia Budi, Surakarta.

Nuryanti, L. dan Rahman, A. Y. 2008. Pengaruh Variasi dan Kemasan Produk terhadap Keputusan Pembelian Teh Kotak Ultrajaya. Jurnal Pendidikan Manajemen Bisnis. 7 (14) : 1-13.

Novi, M. 2016. Analisis SWOT Sebagai Strategi Untuk Memperluas Pangsa Pasar Pada UMKM Mamin di Surabaya. Seminar Nasional Ekonomi Universitas Negeri Surabaya. 204-214.

Ommani, A. R. 2011. Strengths, weakness, opportunities and threats (SWOT) analysis for farming sistem businesses management : case pf wheat farmers of Shadervan District, Shoushtar Township, Iran. African journal of business management. 5 (22) : 9448-9454.

Suherman O. Y. 2012. Pengeringan Bunga Rosela (Hibiscus sabdariffa L.) menggunakan Pengering Rak Udara Resirkulasi. Jurnal Teknologi Kimia dan Industri. 1 (1) : 1 - 6.

Evangelos, T. 2000. Multi-criteria Decision Making Methods: A Comparative Study. Springer

Purwono, J., Sri S. dan Rara T. P. 2015. Strategi Pengembangan Bisnis Rumah Tempe Indonesia di Kota Bogor, Propinsi Jawa Barat. Jurnal Neo-Bis. 9 (1) : 60 - 71.

Yu, H. J. dan Kincade, D. H. 2001. Effects of product image at three stages of the consumer decision process for apparel products: alternative evaluation, purchase and post-purchase. Journal of Fashion Marketing and Management. 5 (1): $29-43$.

Yunan. 2009. Analisis Faktor-Faktor yang Mempengaruhi Pertumbuhan Ekonomi Indonesia. Journal Master Theses Economy Development. Universitas Sumatera Utara. http://repository.usu.ac.id/handle/123456789/7200. Diakses 7 juni 2017. 